\title{
Calcitonin Receptor-Like Receptor Is Expressed on Gastrointestinal Immune Cells
}

\author{
Stefanie Hagnera J ens Knauera Rainer Haberbergerb Burkhard Göke ${ }^{\mathrm{c}}$ \\ Karlheinz Voigta Gerard Patrick McGregora \\ aInstitute of Physiology, Philipps University, Marburg, bInstitute of Anatomy and Cell Biology, \\ J ustus Liebig University, Giessen, 'Department of Medicine II, University of Munich, Klinikum Grosshadern, \\ Munich, Germany
}

\author{
Key Words \\ Gut immune cells - Calcitonin gene-related peptide . \\ Calcitonin receptor-like receptor
}

\begin{abstract}
Background/Aims: Pharmacological and morphological studies suggest that the gut mucosal immune system and local neuropeptide-containing neurones interact. We aimed to determine whether gut immune cells are targets for calcitonin gene-related peptide (CGRP), which has potent immune regulatory properties. Methods: Using density gradient centrifugation, rat lamina propria mononuclear cells (LP-MNCS) and intra-epithelial lymphocytes (IELs) were isolated. RT-PCR was employed for the detection of mRNA of rat calcitonin receptor-like receptor (CRLR), which is considered to represent the pharmacologically defined CGRP receptor-1 subtype, as well as mRNA of the receptor activity-modifying proteins, which are essential for CRLR function and determine ligand specificity. A radioreceptor assay was employed for the detection of specific CGRP binding sites. Results: RT-PCR and DNA sequencing showed that LPMNCS and IELs express CRLR. Incubation of isolated LPMNCs with radiolabelled $\alpha C G R P$ revealed the existence of specific binding sites for CGRP. Conclusion: These
\end{abstract}

novel data indicate that mucosal immune cells of the rat gut are a target for CGRP and provide significant evidence that CGRP functions as an immune regulator in the gut mucosa.

Copyright $@ 2002$ S. Karger AG, Basel

\section{Introduction}

The gastrointestinal tract plays a unique and vital immunological role [1]. The gut contains several neuropeptides that are known to have immune regulatory actions in other tissues, and there is a lot of evidence that peptide-containing neurones may play a role in regulating gut immunity [2-5]. For example, Peyer's plaques, which are the primary lymphoid tissue of the gut mucosa, and the lamina propria, which contains many immune cells and is the effector site of the gut immune system, are supplied by nerves that contain neuropeptides that are known to exert potent effects on immune cells [6].

In particular, the neuropeptides substance $P$ and calcitonin gene-related peptide (CGRP), which are present in gut neurones, have been identified as probable neuroendocrine mediators of the neural control of immune and inflammatory processes in several pathophysiological models in different organs, including the gut [7-10]. Their

\section{KARGER \\ Fax + 41613061234 E-Mail karger@karger.ch www.karger.com}

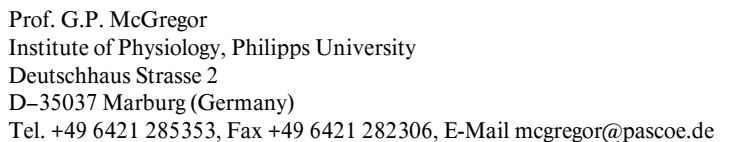


activated release from sensory neurones and their mediation of neurogenic inflammation has been particularly well established in a number of tissues [11, 12]. Both peptides are thought to contribute to inflammatory reactions via effects on the local blood flow - both are potently vasodilatory, and, additionally, substance $P$ stimulates extravasation [13]. There is also considerable evidence that they both act directly on immune cells; from the numerous pharmacological studies, it appears that substance $\mathrm{P}$ promotes inflammatory reactions while CGRP dampens these processes [10].

There is generally limited information concerning the distribution of neuropeptide receptors on immune cells, particularly those of the gut $[14,15]$, and this is hindering progress in understanding the role of neuropeptides in neuro-immune reactions. The only cloned receptor protein that has so far been identified as a receptor for CGRP is the calcitonin receptor-like receptor (CRLR) [16]. CRLR is a G-protein-associated, seven trans-membrane receptor that has been shown to correspond to the pharmacologically defined CGRP receptor-1 subtype [17] and which appears to be widely distributed in the body.

Both CGRP and adrenomedullin can act via CRLR, but the ligand specificity of the receptor is determined by the co-expression of particular accessory proteins, receptor activity-modifying protein (RAMP)-1, -2 and -3 [18, 19]. CRLR needs to associate with a RAMP protein in order to function as a membrane receptor. The molecular interaction of CRLR with RAMP-1 generates a functional CGRP receptor, while the interaction of CRLR with RAMP-2 or RAMP-3 provides a functional and specific adrenomedullin receptor [19].

Here, we describe experiments that were conducted to determine whether CGRP receptors are expressed on gut immune cells. Using radiolabelled CGRP in autoradiographic analysis of rat intestine, we have previously demonstrated the existence of specific CGRP binding sites in several mucosal and submucosal areas [20]. Particularly dense staining was obtained in the lamina propria. However, such studies do not allow resolution at the cellular level.

In order to obtain definitive evidence of the expression of CGRP receptors by gut immune cells, we have combined molecular and biochemical analysis of isolated lamina propria mononuclear cells (LP-MNCs) and intra-epithelial lymphocytes (IELs) from the rat. In this work, we obtained novel evidence of the expression of the mRNAs of CRLR and RAMP-1, -2 and -3 and of the presence of specific CGRP binding sites in gut mucosal immune cells.

\section{Materials and Methods}

\section{Animals}

Adult male Wistar rats were used in all experiments.

\section{Cell Isolation}

IELs were isolated by a technique originally described by Kearsey and Stadnyk [21]. Briefly, the entire small intestine was removed from 4-8 rats (depending on required cell number) and the lumen was washed with calcium- and magnesium-free Hanks' balanced salts solution. All Peyer's patches and adherent mesentery were excised with a scalpel and the intestines were opened longitudinally before being cut into two pieces and vortexed in PBS-DTT to remove mucus and cell debris. The epithelium with the IELs was dissected from the underlying mucosa by vortexing the cells in RPMI-FCS-PS-HEPES medium. Purification of IELs from the cell suspension was performed to release lymphocytes from clumps of epithelium, by centrifugation of the cells through Percoll (see below).

To isolate LP-MNCs, the treated tissue received three more 45-min incubations with EDTA, and the released cells were discarded. The remaining tissue was digested 4 times for $15 \mathrm{~min}$ at $37^{\circ} \mathrm{C}$ in $1 \mathrm{mg} / \mathrm{ml}$ collagenase (Gibco, Eggenstein, Germany), then pressed through a mesh sieve to free any trapped cells. LP-MNCs were purified on a discontinuous Percoll gradient (45\%/75\%). The cell pellet was suspended in a $45 \%$ Percoll solution. A second $75 \%$ Percoll solution was layered under the $45 \%$ solution, and the discontinuous Percoll gradient was then centrifuged at $350 \mathrm{~g}$ for $30 \mathrm{~min}$. Both cell populations were collected from the interface between the $45 \%$ and $75 \%$ Percoll layers and stored in RPMI-FCS-PSG-HEPES medium.

The isolated cells were counted and cell viability was determined using trypan blue staining of cells after recovering them and washing them free of Percoll (viability was $>96 \%$ ).

\section{Antibodies Used in Phenotypic Analyses}

For flow cytometry analysis, the following FITC-conjugated monoclonal antibodies (Serotec, Wiesbaden, Germany) were used: MRC OX-22 (anti-CD45RC), MRC OX-8 (anti-CD8), W3/25 (antiCD4) and MRC OX-33 (anti-CD45, B cell form).

\section{Staining and Flow Cytometry}

For single-colour immunofluorescence, $1 \times 10^{6}$ cells were incubated in $100 \mu \mathrm{l}$ of a saturating concentration of FITC antibody in PBS with $0.5 \%$ bovine serum albumin (BSA) for $30 \mathrm{~min}$ at $4{ }^{\circ} \mathrm{C}$, with frequent mixing. After incubation, cells were washed twice, resuspended in $500 \mu \mathrm{l}$ of PBS-BSA and analysed on a Becton Dickinson FACScan flow cytometer. Results were generated using the FACScan Research computer software program. Cells from the entire contour plot were examined for fluorescence. The percentage of cells labelled by each monoclonal antibody was calculated in comparison with cells stained with an isotype control antibody.

\section{Preparation of CGRP Solutions}

CGRP was dissolved in sterile PBS-BSA. Stock solutions were aliquoted at $10^{-4} \mathrm{M}$ in Minisorb tubes (NUNC GmbH \& Co, Wiesbaden, Germany) and frozen at $-70^{\circ} \mathrm{C}$ until use. Working concentrations were also prepared in Minisorb tubes.

\section{$R T-P C R$}

Total RNA was isolated by phenol-chloroform extraction of guanidium-isothiocyanate lysates according to the protocol of the 
Table 1. Primers for RT-PCR

\begin{tabular}{|c|c|c|c|}
\hline Gene & Sequence & $\begin{array}{l}\text { Position } \\
\text { nucleotides }\end{array}$ & $\begin{array}{l}\text { PCR } \\
\text { product, bp }\end{array}$ \\
\hline \multicolumn{4}{|l|}{$C R L R$} \\
\hline Forward primer & 5'GACATCCAGATAGTAACAGG-3' & $1016-1035$ & \multirow[t]{2}{*}{705} \\
\hline Reverse primer & 5'CAATGCCAAGTAGTGGTACC-3' & $1720-1701$ & \\
\hline \multicolumn{4}{|l|}{$R A M P-1$} \\
\hline Forward primer & 5'CAATCCGGAAGTGGACAAGT-3' & $271-290$ & \multirow[t]{2}{*}{197} \\
\hline Reverse primer & 5'ACACCTACACGATGCCСТCT-3' & $467-448$ & \\
\hline \multicolumn{4}{|l|}{$R A M P-2$} \\
\hline Forward primer & 5'TACAGCAACCTGCGGTATTG-3' & $315-334$ & \multirow{2}{*}{203} \\
\hline Reverse primer & 5’AGGAAAGGGATGAGGCAGAT-3' & $517-498$ & \\
\hline \multicolumn{4}{|l|}{$R A M P-3$} \\
\hline Forward primer & 5’TCTTGTTGACCGTGGCTATG-3' & $409-428$ & \multirow[t]{2}{*}{120} \\
\hline Reverse primer & 5'CTGGGCGACATTCTTCTAGC-3' & $528-509$ & \\
\hline \multicolumn{4}{|l|}{ NK-1 receptor } \\
\hline Forward primer & 5'CATCGTGGTGACTTCCGTGG-3' & $700-719$ & \multirow[t]{2}{*}{504} \\
\hline Reverse primer & 5'GAGGCAGGAAGTAGATCAGT-3' & $1202-1183$ & \\
\hline \multicolumn{4}{|l|}{ NK-3 receptor } \\
\hline Forward primer & 5'AGCGAGTGGTACTTTGGCG-3' & $632-650$ & \multirow[t]{2}{*}{447} \\
\hline Reverse primer & 5'GACATCCAGATAGTAACAGG-3' & $1078-10$ & \\
\hline
\end{tabular}

The primers were designed based on the published cDNA sequences of rat CRLR, rat RAMP-1, rat RAMP-2, rat RAMP-3, rat NK-1 receptor and rat NK-3 receptor (GenBank accession Nos. L27487, AF1550, AF181551, AF181552, NM012667 and NM017053, respectively).

manufacturer (Qiagen, Hilden, Germany) and treated with deoxyribonucleases (MBI Fermentas, St. Leon-Rot, Germany) for $15 \mathrm{~min}$ at $37^{\circ} \mathrm{C}$ before converting into cDNA. For the RT step, $1 \mu \mathrm{g}$ of total RNA was incubated in a final volume of $20 \mu 1$ containing $200 \mathrm{U}$ of MMV reverse transcriptase, then stored at $-20^{\circ} \mathrm{C}$ until required for PCR. PCR amplification was performed in a final volume of $50 \mu \mathrm{l}$ containing $1.5 \mu M \mathrm{MgCl}_{2}, 50 \mu M$ dNTPs, $0.1 \mu M$ of each primer and $1 \mathrm{U}$ of AmpliTaq polymerase (Perkin Elmer, Überlingen, Germany). Negative controls were performed by either omitting the reverse transcriptase from cDNA synthesis or by omitting cDNA from the PCR amplifications. Product specificities were confirmed by DNA sequence analysis using an ABI Prism Genetic Analyzer (Perkin Elmer). Sequences of all the primers used in this work are listed in table 1 .

\section{Radioligand Binding}

${ }^{125} \mathrm{I}-\left[\mathrm{His}_{10}\right] \alpha$-CGRP was prepared with a modification of the radioiodination procedure that has been previously employed [22]. Briefly, oxidative conditions were used (employing Iodogen, from Pierce, Rockford, Ill., USA) at $\mathrm{pH} 8.5$ in order to facilitate iodination of histidine. The reaction mixture was then fractionated using reversed-phase HPLC, and pure monoiodinated peptide with a specific activity of greater than $2,000 \mathrm{Ci} / \mathrm{mmol}$ was obtained.

$5 \times 10^{6}$ to $1 \times 10^{7}$ IELs or LP-MNCs were incubated, in duplicate, with $150,000-250,000 \mathrm{cpm}$ of ${ }^{125} \mathrm{I}_{-}\left[\mathrm{His}_{10}\right] \alpha-C G R P(150-$ $200 \mathrm{p} M$ ) in HBSS-HEPES-0.1\% BSA (final volume of $0.25 \mathrm{ml}$ ). Spe- cific binding was defined as the difference between total and nonspecific binding, which was determined separately and in duplicate by including unlabeled CGRP at a final concentration of $10^{-6} M$ in the incubation mixture. After incubation for $1 \mathrm{~h}$ at RT, cells were centrifuged for $5 \mathrm{~min}$ at $10.000 \mathrm{~g}$ at $4^{\circ} \mathrm{C}$. Cells were resuspended in ice-cold incubation buffer. Each suspension was then transferred to fresh tubes and centrifuged again, before the cell pellet was counted using an automatic $\gamma$-counter. SK-N-MC-cells, which are a clonal cell line that express the CRLR [23], were used as a positive control.

\section{Results}

\section{Isolation of Gut Mucosal Immune Cells}

LP-MNCs and IELs were isolated from rat intestine. The average yield of LP-MNCs was $1 \pm 1 \times 10^{7}$ cells per rat $(\mathrm{n}=10)$, and for IELs, it was $5 \pm 1 \times 10^{6}$ cells per rat $(n=15)$. Isolated cells were consistently greater than $95 \%$ viable, and any dead cells were typically large non-lymphocytes. Flow cytometry of the entire population recovered from the $45-75 \%$ Percoll interface revealed a nearly pure lymphocyte fraction for both fractions ( $>95 \%$ of cells were CD45 positive; fig. 1). The IEL preparation con- 


\section{intra-epithelial lymphocytes (IEL)}
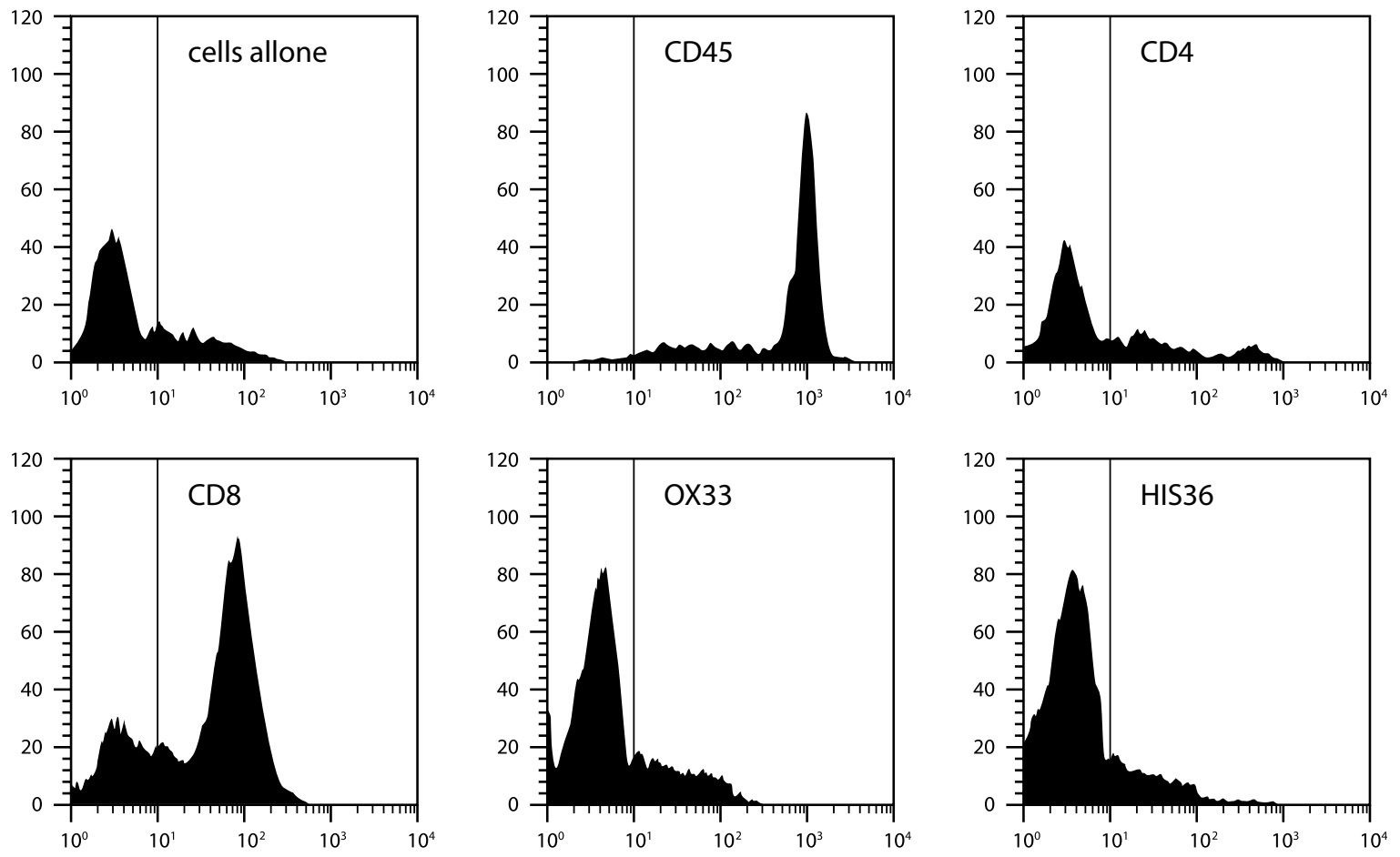

lamina propria mononuclear cells (LP-MNC)


1 
Fig. 2. a Evidence of expression of CRLR and $\mathrm{NK}$ receptors (Nk1R, Nk2R) in rat IELs (lanes 1) and rat LP-MNCs (lanes 2). RTPCR analysis of isolated rat IELs and LPMNCs indicated that they express the CGRP receptor-1 and the NK-1 receptor, but not the NK-2 receptor. Analysis of RNA from rat lung (lanes 3), which is known to express all three receptors, served as the control. b Evidence of expression of RAMP-1, -2 and -3 (R1, R2 and $R 3$, respectively) in rat IELs and rat LP-MNCs.

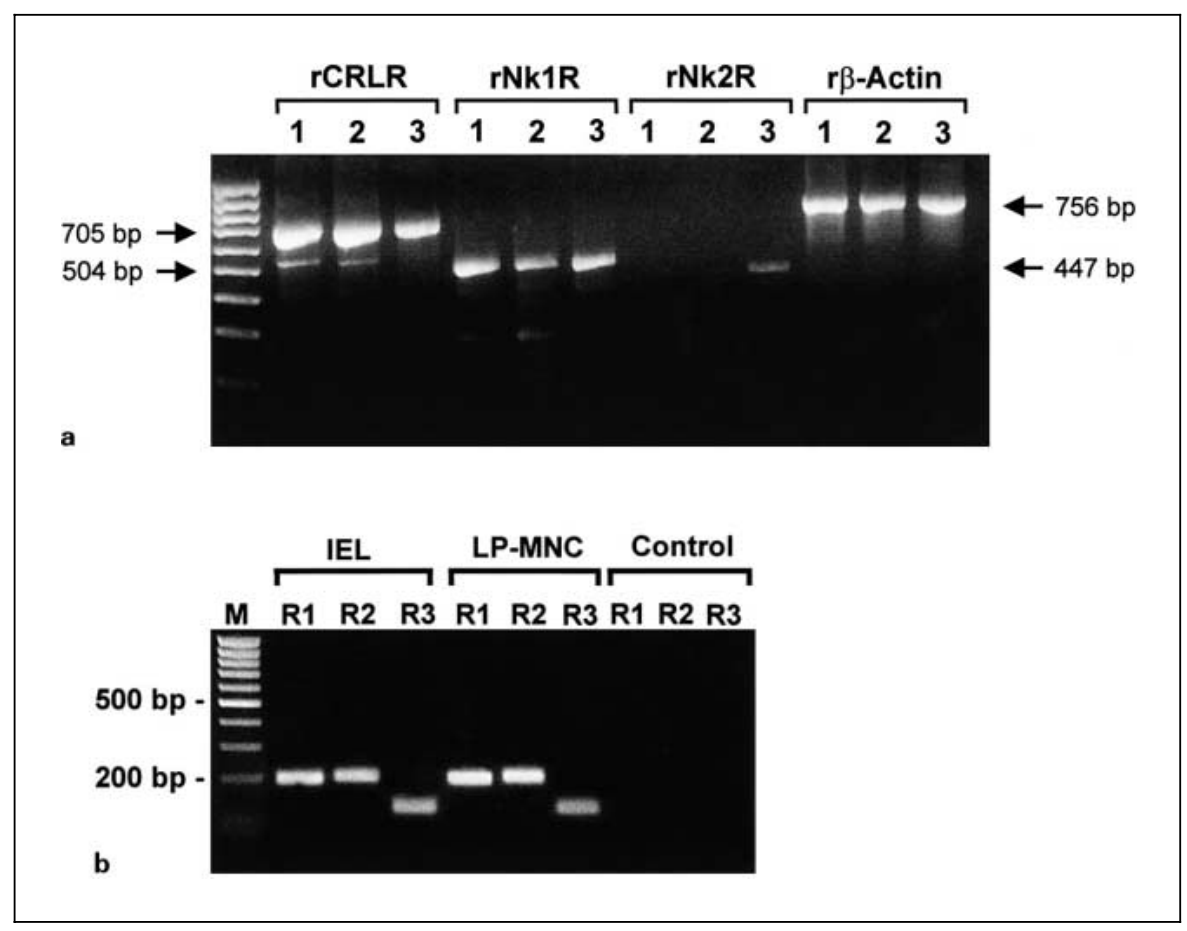

tained mostly CD8-positive cells (75-80\%), a few CD4positive cells (20-25\%) and $<5 \%$ B lymphocytes. The LPMNC preparation contained a higher level of CD4-positive cells than CD8-positive cells (ratio 2.5:1) and $>25 \%$ B lymphocytes.

\section{RT-PCR Analysis}

In order to determine whether rat LP-MNCs and IELs express the mRNAs for CRLR and RAMP-1, -2 and -3 , we performed RT-PCR using specific primers (table 1). Ethidium bromide staining of the RT-PCR products from rat LP-MNCs and IELs are shown in figure $2 \mathrm{a}$ and $\mathrm{b}$. For CRLR and neurokinin (NK)-1 receptor, the respective amplification of both IEL and LP-MNC mRNAs showed a single major visible band of approximately $705 \mathrm{bp}$ (for CRLR) and $504 \mathrm{bp}$ (for NK-1 receptor). These correspond to the sizes of the expected amplified cDNAs, as do the single bands found in the parallel RT-PCR analysis of mRNA from rat lung, which is a tissue known to express both CRLR and NK-1 receptor [24]. No NK-3 receptor

Fig. 1. Characterisation by FACS analysis of isolated rat IELs and LP-MNCs using fluorescent-labelled antibodies directed against characteristic cell surface marker proteins (see Materials and Methods).

Gut Immune Cells Express CRLR
cDNA could be amplified from IEL and LP-MNC mRNAs, in contrast to the amplified cDNA from rat lung. Figure $2 b$ shows that, for each of the three RAMPs, single major bands of the expected size were detected: for RAMP-1, 197 bp, for RAMP-2, 203 bp, and for RAMP-3, $120 \mathrm{bp}$. Reverse-transcribed $\beta$-actin cDNA was used as internal control for comparison between samples. To further confirm the specificity of the amplified RT-PCR product, sequence analysis of the CRLR transcript in LPMNCs and IELs was performed (data not shown).

\section{Radioligand Binding Studies}

Using a protocol with which high-affinity binding of ${ }^{125} \mathrm{I}-\left[\mathrm{His}_{10}\right] \alpha-\mathrm{CGRP}$ on SK-N-MC cells could be demonstrated, we were able to show that $0.5-1.0 \times 10^{7} \mathrm{LP}-$ MNCs bind a detectable amount of ${ }^{125} \mathrm{I}-\left[\mathrm{His}_{10}\right] \alpha$-CGRP present at a concentration of 150-200 $\mathrm{p} M$. This represents binding of high affinity and was significantly displaced by CGRP but not by substance P (fig. 3).

\section{Discussion}

It has become apparent in recent years that a major component of the body's immune system resides in the gut and that the enteric immune system exhibits some

Digestion 2002;66:197-203 


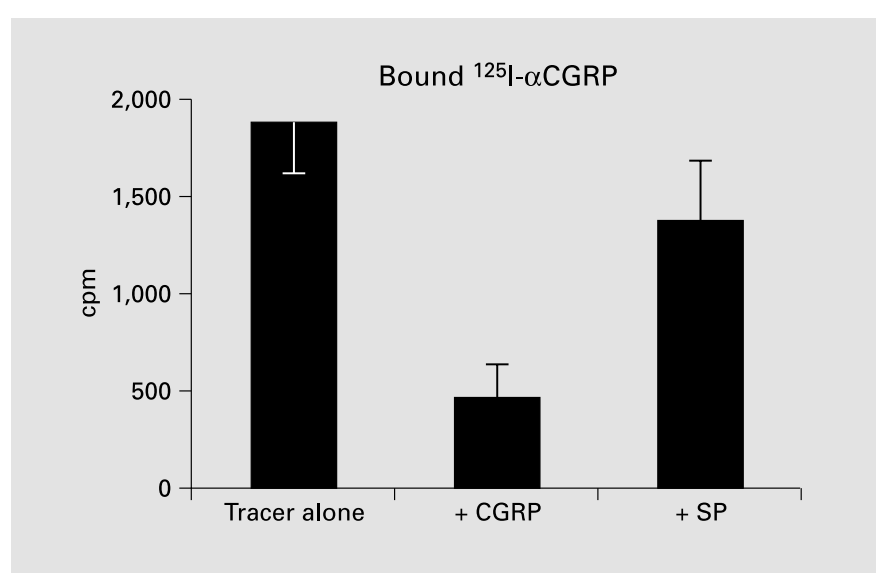

Fig. 3. Binding of ${ }^{125} \mathrm{I}-\alpha \mathrm{CGRP}$ on LP-MNCs isolated from the rat gut. The amount of ${ }^{125} \mathrm{I}-\alpha \mathrm{CGRP}$ bound is shown as counts per minute (cpm) for ${ }^{125}$ I- $\alpha$ CGRP (tracer) alone, in the presence of $\alpha$ CGRP $(1 \mu M)$ and in the presence of substance P (SP; $1 \mu M)$.

unique and important features [25]. In particular, it is evident that the gut mucosal immune system is normally in an activated state. The notion that the gut immune cells are under neural influence is mostly supported by morphological studies that have revealed that neuropeptidecontaining nerve endings are in close proximity to gut mucosal immune cells [2, 4]. Neuropeptides such as CGRP and substance $P$ are known to have immune regulatory effects. It has been shown that CGRP has direct effects on immune cells isolated from the skin [26], from lymph nodes [27] and from the thymus and spleen [28], but not so far in the gut. Following our observation that the lamina propria of the rat gut contains high levels of binding sites for CGRP [20], here we provide the first evidence that immune cells of the lamina propria, as well as IELs, express receptors for CGRP, which is novel evidence that gut immune cells are indeed targets for CGRP.

First of all, we were able to demonstrate, by FACS analysis, that we obtained a pure lymphocyte fraction (over $95 \%$ of the cells were CD45 positive). The FACS analysis also confirmed already published data that the IEL preparation contains mostly CD8-positive cells whereas the LP-MNC preparation contains a higher level of CD4-positive cells [25]. Employing RT-PCR and sequence analysis of the resulting single DNA product, we obtained novel evidence that CRLR mRNA is expressed by both LP-MNCs and IELs of the rat. We have also shown here by RT-PCR that gut mucosal immune cells of the rat express the substance $\mathrm{P}$ receptor (NK-1 receptor), which confirms what has already been shown in human [14] and mouse [15] gut immune cells. This supports the notion that substance $\mathrm{P}$ may play a special role in gut immunity [6] and indicates that our findings with CRLR should be extended to CGRP and its role in gut immunity.

The RAMPs are accessory proteins that are necessary for CRLR to function as a receptor, and they also determine the receptor's ligand specificity [19]. The detection of the three RAMP mRNAs in both LP-MNC and IEL extracts means that there may be different functional forms of CRLR present. The co-expression of RAMP-1 allows CRLR to function as a CGRP receptor. Using a protocol with which high-affinity binding of ${ }^{125} \mathrm{I}-\alpha \mathrm{CGRP}$ could be demonstrated, we showed that LP-MNCs bind ${ }^{125}$ I- $\alpha$ CGRP. The specificity of the binding was demonstrated by its displacement by non-radiolabelled $\alpha$ CGRP. Since these experiments required such a high amount of cells, the yield of cells from a single preparation of 8 rats was insufficient to allow full analysis of the kinetics of binding. Also, no binding could be demonstrated in IELs. Both LP-MNCs and IELs are heterogenous populations of immune cells, and it is very possible that only a subpopulation of each cell fraction expresses binding sites, which further reduces the effectiveness of such radioligand binding studies.

The co-expression of RAMP-2 and RAMP-3 with CRLR suggests the presence of functional adrenomedullin receptors [19]. Adrenomedullin and CGRP have a similar molecular structure and biological activity. Like CGRP, adrenomedullin is present in the healthy gastrointestinal tract but is actually present at much lower levels [29]. However, there are increased levels of adrenomedullin in the gut during inflammatory states, such as in sepsis [30]. This is also reported to occur in other tissues, as well as the fact that adrenomedullin is inducible in macrophages [31]. Therefore, it would be of interest, in further studies, to investigate the possible presence of functional adrenomedullin receptors on gut mucosal immune cells.

LP-MNCs represent the 'effector' arm of the gut mucosal immune system, which is considered to be in a state of 'physiological' inflammation [32]. In addition to being in an 'activated state', which is, for example, evident from the high level of expression of IL-2 and its receptor by lamina propria immune cells, the gut immune system exhibits an 'active' non-responsiveness that is vital in order to avoid reactions to non-harmful antigens that are derived from the gut flora and diet. In other tissues and in different experimental models, pharmacological studies have revealed that CGRP potently dampens immune 
responses [28, 33, 34]. Therefore, CGRP may play a similar role in the gut mucosa and contribute to the tight regulation of immunity in the healthy gut mucosa by acting directly on immune cells.

In light of our results, it would be appropriate to investigate the direct effects of this neuropeptide on gut mucosal immune cells under both healthy and inflammatory conditions. The innervation of the gut mucosa plays a vital role in regulating the function [5] and structural integrity [35] of the gut mucosa and this is likely to include effects on the gut immune system. CGRP can be considered a major candidate mediator of the endocrine control of gut immunity.

\section{Acknowledgement}

This study was supported by the P.E. Kempkes Stiftung, Marburg, Germany.

\section{References}

1 MacDonald TT: T cell immunity to oral allergens. Curr Opin Immunol 1998;10:620-627.

2 Bienenstock J, Croitoru K, Ernst PB, Stanisz AM: Nerves and neuropeptides in the regulation of mucosal immunity. Adv Exp Med Biol 1989;257:19-26.

3 Bellinger DL, Lorton D, Romano TD, Olschowka JA, Felten SY, Felten DL: Neuropeptide innervation of lymphoid organs. Ann NY Acad Sci 1990;594:17-33.

4 Stead RH, Bienenstock J, Stanisz AM: Neuropeptide regulation of mucosal immunity. Immunol Rev 1987;100:333-359.

5 Wood JD, Alpers DH, Andrews PL: Fundamentals of neurogastroenterology. Gut 1999; 45(suppl 2):II6-II16.

6 Shanahan F, Anton P: Role of peptides in the regulation of the mucosal immune and inflammatory response; in Walsh JH, Dockray GJ (eds): Gut Peptides: Biochemistry and Physiology. New York, Raven, 1994, pp 851-867.

7 Bozic CR, Lu B, Hopken UE, Gerard C, Gerard NP: Neurogenic amplification of immune complex inflammation. Science 1996;273: 1722-1725.

8 Mantyh PW, Catton MD, Boehmer CG, Welton ML, Passaro EP Jr, Maggio JE, Vigna SR: Receptors for sensory neuropeptides in human inflammatory diseases: Implications for the effector role of sensory neurons. Peptides 1989; 10:627-645.

9 Pothoulakis C, Castagliuolo I, LaMont JT: Nerves and intestinal mast cells modulate responses to enterotoxins. News Physiol Sci 1998:13:58-63.

10 Holzer P: Implications of tachykinins and calcitonin gene-related peptide in inflammatory bowel disease. Digestion 1998:59:269-283.

11 Scholzen T, Armstrong CA, Bunnett NW, Luger TA, Olerud JE, Ansel JC: Neuropeptides in the skin: Interactions between the neuroendocrine and the skin immune systems. Exp Dermatol 1998;7:81-96.

12 Barnes PJ: Neuropeptides and asthma. Am Rev Respir Dis 1991;143:S28-S32.

13 Holzer P: Neurogenic vasodilatation and plasma leakage in the skin. Gen Pharmacol 1998; 30:5-11.
14 Goode T, O'Connell J, Sternini C, Anton P, Wong H, O'Sullivan GC, Collins JK, Shanahan F: Substance P (neurokinin-1) receptor is a marker of human mucosal but not peripheral mononuclear cells: Molecular quantitation and localization. J Immunol 1998;161:2232-2240.

15 Qian BF, Zhou GQ, Hammarstrom ML, Danielsson A: Both substance $\mathrm{P}$ and its receptor are expressed in mouse intestinal $\mathrm{T}$ lymphocytes. Neuroendocrinology 2001;73:358-368.

16 Chang CP, Pearse RV 2nd, O'Connell S, Rosenfeld MG: Identification of a seven transmembrane helix receptor for corticotropin-releasing factor and sauvagine in mammalian brain. Neuron 1993;11:1187-1195.

17 Poyner D: Pharmacology of receptors for calcitonin gene-related peptide and amylin. Trends Pharmacol Sci 1995;16:424-428.

18 Foord SM, Marshall FH: RAMPs: Accessory proteins for seven transmembrane domain receptors. Trends Pharmacol Sci 1999;20:184187.

19 McLatchie LM, Fraser NJ, Main MJ, Wise A, Brown J, Thompson N, Solari R, Lee MG, Foord SM: RAMPs regulate the transport and ligand specificity of the calcitonin-receptor-like receptor. Nature 1998;393:333-339.

20 Ozdemir FA, Berghofer P, Goke R, Goke B, McGregor GP: Specific calcitonin gene-related peptide binding sites present throughout rat intestine. Peptides 1999;20:1361-1366.

21 Kearsey JA, Stadnyk AW: Isolation and characterization of highly purified rat intestinal intraepithelial lymphocytes. J Immunol Methods 1996;194:35-48.

22 McGregor GP, Gaedicke G, Voigt K: Neurokinin-immunoreactivity in human neuroblastomas. Evidence for selective expression of the preprotachykinin (PPT) II gene. FEBS Lett 1990;277:83-87.

23 Muff R, Stangl D, Born W, Fischer JA: Comparison of a calcitonin gene-related peptide receptor in a human neuroblastoma cell line (SKN-MC) and a calcitonin receptor in a human breast carcinoma cell line (T47D). Ann NY Acad Sci 1992;657:106-116.

24 Fluhmann B, Lauber M, Lichtensteiger W, Fischer JA, Born W: Tissue-specific mRNA expression of a calcitonin receptor-like receptor during fetal and postnatal development. Brain Res 1997;774:184-192.
25 Brandtzaeg P: Development and basic mechanisms of human gut immunity. Nutr Rev 1998; 56:S5-S18.

26 Hosoi J, Murphy GF, Egan CL, Lerner EA, Grabbe S, Asahina A, Granstein RD: Regulation of Langerhans cell function by nerves containing calcitonin gene-related peptide. Nature 1993;363:159-163.

27 Levite M: Neuropeptides, by direct interaction with $\mathrm{T}$ cells, induce cytokine secretion and break the commitment to a distinct $\mathrm{T}$ helper phenotype. Proc Natl Acad Sci USA 1998;95: 12544-12549.

28 Bulloch K, McEwen BS, Nordberg J, Diwa A, Baird S: Selective regulation of T-cell development and function by calcitonin gene-related peptide in thymus and spleen. An example of differential regional regulation of immunity by the neuroendocrine system. Ann NY Acad Sci 1998;840:551-562.

29 Sakata J, Asada Y, Shimokubo T, Kitani M, Inatsu H, Kitamura K, Kangawa K, Matsuo H, Sumiyoshi A, Eto T: Adrenomedullin in the gastrointestinal tract. Distribution and gene expression in rat and augmented gastric adrenomedullin after fasting. J Gastroenterol 1998; 33:824-834.

30 Zhou M, Chaudry ICH, Wang P: The small intestine is an important source of adrenomedullin release during microbial sepsis. Am J Physiol Regul Integr Comp Physiol 2001;281: R654-R660.

31 Elsasser TH, Kahl S: Adrenomedullin has multiple roles in disease stress: Development and remission of the inflammatory response. $\mathrm{Mi}$ crosc Res Tech 2002;57:120-129.

32 Levine AD, Fiocchi C: Regulation of life and death in lamina propria T cells. Semin Immunol 2001;13:195-199.

33 Asahina A, Hosoi J, Beissert S, Stratigos A, Granstein RD: Inhibition of the induction of delayed-type and contact hypersensitivity by calcitonin gene-related peptide. J Immunol 1995;154:3056-3061.

34 Sakuta H, Inaba K, Muramatsu S: Calcitonin gene-related peptide enhances apoptosis of thymocytes. J Neuroimmunol 1996;67:103-109.

35 Bjerknes M, Cheng H: Modulation of specific intestinal epithelial progenitors by enteric neurons. Proc Natl Acad Sci USA 2001;98:1249712502. 